Jurnal Konstruksi Hukum | ISSN: 2746-5055

Vol. 2, No. 3, September 2021 Hal. 650-655| Tersedia online di https://www.ejournal.warmadewa.ac.id/index.php/jukonhum

DOI:http://doi.org/10.22225/jkh.2.3.3673.650-655

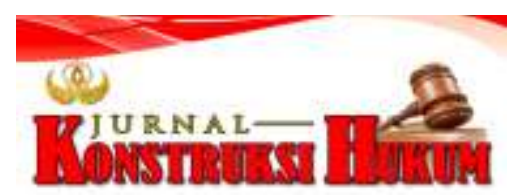

\title{
PERTANGGUNG JAWABAN PERUSAHAAN DAERAH PARKIR TERHADAP KONSUMEN DITINJAU DARI PERATURAN DAERAH KOTA DENPASAR NOMOR 11 TAHUN 2005 TENTANG SISTEM PENYELENGGARAAN
}

\author{
Kadek Rizak Agung, Ni Komang Arini Styawati \& I Wayan Arthanaya \\ Fakultas Hukum Universitas Warmadewa, Denpasar-Bali, Indonesia \\ rizalartwan@gmail.com, arinistyawati@gmail.com \& I Wayan Arthanaya
}

\begin{abstract}
Abstrak
Peraturan Daerah Nomor 11 Tahun 2005 yang mengatur mengenai sistem penyelenggaraan perparkiran, dalam ketentuan tersebut ditentukan bahwa jika konsumen kehilangan kendaraan bermotor di tempat yang dipungut retribusinya perusahaan daerah parkir Kota Denpasar memberikan ganti rugi. Tetapi masih banyak masyarakat yang tidak mengetahui tentang adanya ganti rugi tersebut. Tujuan penelitian ini adalah untuk menelaah upaya konsumen yang dirugikan dalam rnenuntut ganti rugi dan mekanisme pertanggung jawaban perusahaan daerah parkir Kota Denpasar atas kelalaian yang menyebabkan kehilangan kendaraan bermotor milik konsumen di Kota Denpasar. Penelitian ini menggunakan metode penelitian yuridis empiris, dengan jenis pendekatan yang digunakan adalah pendekatan fakta dan pendekatan perundang-undangan. Maka hasil penelitian ini menunjukkan konsumen dapat menuntut ganti rugi karena kehilangan kendaraan di tempat yang dipungut retribusinya di Kota Denpasar dengan dua bentuk yaitu non litigasi (diluar pengadilan) atau litigasi (jalur pengadilan). Mekanisme pertanggung jawaban perusahaan daerah parkir Kota Denpasar ketika memberikan ganti rugi melalui non litigasi yaitu dengan cara memberikan santunan yang telah ditetapkan. Mekanisme perusahaan daerah parkir Kota Denpasar ketika memberikan ganti rugi yaitu dibayar paling lambat 7 (tujuh) hari mulai berkas pengajuan klaim dikabulkan, namun kejadian diluar kehilangan kendaraan bukan tanggung jawab perusahaan daerah parkir Kota Denpasar.
\end{abstract}

Kata Kunci: Tanggung Jawab, Perusahaan Daerah Parkir, Konsumen

\begin{abstract}
Regional Regulation Number 11 the year 2005 concerning the system of parking arrangement states, the regulation states if the consumer loses a vehicle in the place where the retribution is levied then Denpasar Parking Company will provide the compensation. However, there is still a lot of society that does not know about compensation regulation. The purposes of the research are to analyze the consumer's effort who have suffered losses in demanding the compensation and the responsibility of Denpasar Parking Company due to the loss of vehicles in Denpasar city. The method used is empirical legal research and the approach used is the statute approach and fact approach. The results of this stud y show the consumer who demands compensation for the losses in the Denpasar City area can be done in 2 ways outside the court and in court. Carving compensation through non -litigation from Denpasar Parking Company is by giving compensation that has been set. The mechanism of Denpasar Parking Company in providing the compensation is the compensation should be paid no later than 7 days afler the claim submission file is received, but any incidents outside the loss of the vehicle are not the responsibility of the Denpasar Parking Company.
\end{abstract}

Keyword: Responsibility, Parking Company, Consume

\section{PENDAHULUAN}

Transportasi atau kendaraan merupakan salah satu komponen yang sangat penting bagi setiap orang di zaman ini (Sardi \& Agung, 2021). Oleh karenanya, pengaturan kendaraan di tempat umum sangatlah penting agar tercapainya tata ruang kota yang teratur. Sistem penyelenggaraan perparkiran 
yang akan diteliti dilakukan di Kota Denpasar, dalam Pasal 1 angka (8) hukum lingkungan daerah Denpasar nomor 11 tahun 2005 berkaitan dengan penanganan perparkiran disebutkan parkir merupakan menaruh serta meninggalkan selama sementara alat transportasi di kawasan parkir dan sudah diputuskan serta membayar biaya pelunasan. Area parkir yang telah ditentukan tercantum selaras Pasal 1 angka (9) dan (10) hukum lingkungan daerah Denpasar nomor 11 tahun 2005 berkaitan dengan penanganan perparkiran dibagi membentuk dua yaitu area parkir pinggir jalan masyarakat dan juga area parkir tertentu.

Adapun permasalahan tentang sistem penanganan perparkiran adalah tentang ketiadaan alat transportasi yang sudah ditaruh di area parkir dan telah ditetapkan, ketiadaan dan kerusakan alat transportasi menjadi sesuatu yang merugikan, lantaran pemilik kendaraan tersebut sudah menyetor retribusi. Hukum lingkungan Denpasar Nomor 11 tahun 2005 berkaitan dengan penanganan perparkiran mengatur penggunaan jasa parkir di Kota Denpasar. Meningkatnya kemampuan perekonomian di masyarakat jumlah kendaraan pun semakin meningkat. Mewujudkan kenyamanan, keamanan dan ketertiban lalu lintas masyarakat saat mendapatkan pelayanan di bagian perparkiran dengan dalam rangka pemerintah Kota Denpasar mengeinbangkan penghasilan daerah, sistem penyelenggaraan perparkiran pun perlu diatur.

Hak pemerintah daerah untuk rnempertimbangkan tentang megembangkan penghasilan daerah dari perparkiran dalam upaya menggali potensi pendapatan daerah. Dalam mencegah berbagai ketimpangan di dalam penerapannya perlu adanya pengawasan yang baik, sehingga menguntungkan bagi penghasilan pemasukan daerah dan akibat pertanggungjawaban menurut hukum. Salah satu konsumen pengguna jasa parkir di Kota Denpasar adalah Arga Panjaitan umur 21 tahun yang mengalami kehilangan kendaraan bermotor di parkiran pusat Sanglah menerangkan bahwa dirinya tidak mendapatkan santunan dari perusahaan daerah parkir Kota Denpasar lantaran tak mengetahui aturan tersebut sehingga beliau tidak pernah mengurus berkas kehilangan ke pihak perusahaan daerah parkir Kota Denpasar tetapi hanya melapor ke pihak polsek Denpasar Selatan. Mengenai lembaran karcis sebagai tanda pembayaran suatu retribusi pendapatan asli daerah memperlihatkan cakupan perlindungan hukum yang belum berpihak karena dalam Pasal 11 hukum daerah nomor 11 tahun 2005 berkaitan dengan penanganan perparkiran menerangkan pengguna yang dirugikan atas ketiadaan alat transpnrtasi di tempat yang diambil retribusinya, lantas perusahaan daerah parkir kota Denpasar memberikan santunan.

Dalam penelitian terdahulu dijelaskan bahwa dalam penerapannya masih ada saja tukang parkir yang memungut biaya parkir pada area yang memiliki tanda larangan parkir dan ada beberapa oknum tukang parkir yang tidak melayani dengan baik, untuk itu pihak perusahaan melakukan upaya mengevaluasi setiap tahun untuk meningkatkan pelayanan (Putra, 2020). Penelitian selanjutnya, bertujuan untuk mengetahui kekuatan hukum dari aturan yang ditetapkan oleh penyedia jasa parkir, serta unutk memahami penerapan tanggung jawab hukum pelaku usaha parkir terhadap konsumen yang kehilangan kendaraan roda dua (Tamzil, 2019). Penelitian terakhir, mengkaji pertanggungjawaban hukum pelaku usaha penyedia jasa parkir pada hotel di Kota Balikpapan (Putra, 2018). Pada penelitian kali ini peneliti memutuskan untuk mengkaji pertanggungjawaban perusahan daerah ditinjau dari Peraturan Daerah Kota Denpasar Nomor 11 Tahun 2005 Tentang Sistem Penyelenggaraan. Tujuan penelitian ini adalah untuk menelaah upaya konsumen yang dirugikan dalam rnenuntut ganti rugi dan mekanisme pertanggung jawaban perusahaan daerah parkir Kota Denpasar atas kelalaian yang menyebabkan kehilangan kendaraan bermotor milik konsumen di Kota Denpasar.

\section{METODE PENELITIAN}

Saat membahas permasalahan ini, memerlukan tipe analisis hukum empiris, analisis yang memanfaatkan fakta-fakta empiris yang diterima dari watak manusia, baik verbal yang diperoleh melalui wawancara maupun nyata yang diperoleh dengan cara pandangan secara langsung (Soejono 
\& Abdurrahman, 2003). Oleh karena itu, penelitian ini menggunakan pendekatan fakta dan pendekatan perundang-undangan. Dengan teknik pengumpulannya melalui data primer yang dilakukan dengan melihat fakta yang terjadi di masyarakat, sedangkan data sekunder yang dikumpulkan dengan teknik pencatatan, dan kemudian dianalisis dengan teknik interpretasi yang disirnpulkan dengan metode dari induktif ke deduktif.

\section{PEMBAHASAN}

\section{Upaya Konsumen Yang dirugikan dalam Menuntut Ganti Rugi}

Pada hakekatnya perusahaan daerah parkir Kota Denpasar dalam mempertanggung jawabkan pelayanannya kepada konsumen yang dirugikan perlu didasari oleh pilar tanggung jawab. Pilar tanggung jawab menjadi peristiwa yang amat penting pada hukum perlindungan konsumen. Pada masalah pelanggaran hak konsumen dibutuhkan ketelitian saat menguraikan yang berkewajiban serta tanggung jawab betapa maksimal yang dilimpahkan ke pihak-pihak terikat (Tutik \& Febriana, 2010). Dalam perspektif international, hak-hak konsumen harus dilindungi, seperti yang dikemukakan presiden Arnerika Serikat ke-35, John F.Kennedy mengatakan empat hak konsumen yang wajib dijaga adalah:

1.) Hak ketentraman

2.) Hak untuk memilah

3.) Hak menerima penjelasan

4.) Hak untuk didengar (Patrik, 1994).

Konsumen adalah making-masing individu pengguna benda dan/atau jasa yang tersaji pada publik, mau pun atas kebutuhan anggota keluarga, manusia yang lain, diri sendiri dan umat lain dan tanpa akan dijual. Menurut Az. N asution mengemukakan sejumlah batasan atas konsumen yaitu konsumen, konsumen antara dan konsumen akhir (Kristiyanti, 2018). Konsumen memiliki kedudukan yang sangat diperlukan dan harus dilindungi pada saat menjalankan suatu hubungan dengan pelaku usaha. Pilar-pilar yang terlihat berhubungan kedudukan konsumen pada tautan hukum melalui pelaksana bisnis dimulai sejak dogma maupun filosofi yang dimengerti saat ekspedisi riwayat peraturan pengamanan pembeli, kumpulan ini yaitu prinsip (Sardi \& Agung, 2021).

Oleh karena pemakai jasa dalam lingkungan pengamanan peraturan menunjukkan terhadap Undang-U ndang Nomor 8 Tahun 1999 Tentang Perlindungan Konsumen (seterusnya disebut HU PK) wajib diamati selaku halnya cara menyerahkan pengamanan peraturan kepada pemakai pelayanan parkir di daerah Denpasar. Mengenai lingkup UUPK ini bisa dikhususkan pada dua bagian, yaitu:

1. Pengamanan kepada peluang benda yang diberikan bagi pengguna bukan sepadan dengan apa yang sudah disetujui.

2. Pengamanan kepada dijalankannya ketentuan-ketentuan yang tiada rata terhadap pengguna (Meliala, 1993).

Untuk mendapatkan klaim kompensasi pada saat kehilangan kendaraan milik konsumen di Denpasar menurut kesimpulan wawancara bersama dengan I Nyoman Putrawan sebagai Direktur Utama Perusahaan Daerah Parkir Kota Denpasar pada tanggal 1 April 2021 diperlukan beberapa syarat yaitu:

a. Berita acara kejadian dari Perusahaan Parkir Kota Denpasar

b. Surat keterangan kehilangan dari kepolisian setempat

c. Surat blokir kendaraan bermotor dari Ditlantas Polda

d. Buku Pemilik Kendaraan Bermotor (BPKB) dan Surat Tanda Nomor Kendaraan (STNK) asli

e. Bukti karcis yang asli

f. foto copy Kartu Tanda Penduduk pemohon

g. Kunci kontak kendaraan yang hilang

h. Laporan kendaraan bermotor yang hilang diterima paling lambat $3 \times 24$ jam dari saat terjadinya kehilangan kendaraan bermotor. 
Jurnal Konstruksi Hukum

Vol. 2, No. 3, 2021

Penyeleseaian sengketa konsumen dapat juga diselesaikan di badan penyelesaian sengketa konsumen (BPSK) maupun menyalurkan ke badan peleraian pada tempat kedudukan konsumen yang sesuai dengan pasal 23 UUP

\section{Mekanisme Pertanggungjawaban Perusahaan Daerah Parkir Atas Kehilangan Kendaraan Bermotor Milik Konsumen di Kota Denpasar.}

Perusahaan daerah yang mengatur parkir di lingkungan Denpasar sebagai pelaksana usaha, memberikan jasa penyelenggaraan perparkiran harus wajib memenuhi segala kewajiban sebagai pelaksana usaha dan juga harus memenuhi wewenang konsumen jika terjadi kerugian yang diderita. Sesuai dengan PERDA No. 11 Tahun 2005 Pasal 3, perusahaan daerah parkir Kota Denpasar memungut retribusi parkir ditempat parkir pinggir jalan masyarakat dan tempat parkir tertentu sepadan melalui harga yang sudah ditetapkan. Besaran retribusi yang ditetapkan dari perusahaan daerah yang mengatur parkir di Kota Denpasar menurut akhir dari wawancara yang dilaksanakan pada tanggal 1 April 202 I bersama dengan I Nyoman Putrawan sebagai Direktur Utama perusahaan daerah yang mengatur parkir di Kota Denpasar yakni untuk kendaraan rcda 2 (motor) besaran retribusi parkir yang dipungut yaitu sejumlah Rp.1000 dan kendaraan roda 4 (mobil) sebesar Rp. 2.000.

Wujud kewajiban yang dialokasikan perusahaan daerah yang mengatur parkir di Kota Denpasar sebagai pelaksana jasa tentang perparkiran di lingkungan Denpasar atas pengguna parkir yang mendapati kerugian ketiadaan alat transportasi sepadan melalui Pasal 11 PERDA No. 11 Tahun 2005, yaitu perusahaan daerah yang mengatur parkir di Kota Denpasar memberikan bantuan berupa hibah kompensasi atas kerugian dalam bentuk ketiadaan alat transpnrtasi milik pengguna di lingkungan Denpasar. Jumlah bantuan yang dialokasikan perusahaan daerah yang mengatur parkir di Kota Denpasar tentang konsumen yang dirugikan kehilangan kendaraan bermotor setara lewat Pasal 7 ayat (1) Peraturan Walikota (PERWALl) Denpasar No. 30 Tahun 2006 berkenaan panduan perwujudan PERDA No. 11 Tahun 2005 berkenaan dengan penyelenggaraan perparkiran yaitu kehilangan alat transportasi mobil sebesar Rp. 20.000.000.00-, dan kehilangan untuk alat transportasi motor Rp. 6.000.000.00-,.

Dalam Pasal 6 ayat (3) PERDA No. 11 Tahun 2005 menjelaskan bahwa klaim ganti rugi atas kehilangan kendaraan bermotor dibayarkan paling lambat 7 (tujuh) hari kerja dimulai saat berkas pengajuan klaim disetujui secara lengkap dan benar oleh perusahaan daerah parkir Kota Denpasar. Namun untuk kejadian diluar kehilangan kendaraan bermotor seperti kerusakan atau kehilangan bagian kendaraan, atribut berkendara dan lainnya merupakan diluar tanggung jawab perusahaan daerah parkir Kota Denpasar. Apabila semua persyaratan lengkap maka proses pengajuan klaim akan dilanjutkan ke proses selanjutnya namun apabila tidak memenuhi syarat maka proses tidak akan dilanjutkan dan persyaratan dikembalikan ke pelapor. Jika persyaratan klaim ganti rugi lengkap, untuk selanjutnya seksi pelaporan dan pengaduan melakukan cross cek ke lapangan atau ke lokasi kejadian kehilangan kendaraan bermotor untuk mendapatkan informasi terkait kejadian tersebut. Setelah dilakukan cross cek ke lokasi kejadian dan informasi yang diperoleh memenuhi syarat untuk dilakukan klaim, maka untuk selanjutnya akan dibuat berita acara kehilangan. Terdiri dari dua berita acara tersebut yaitu berita acara tentang pemeriksaan kehilangan kendaraan di lokasi kejadian dan berita acara tentang kehilangan kendaraan. Setelah kedua berita acara lengkap, maka selanjutnya seksi pelapor dan pengaduan melaporkan ke pimpinan melalui Kepala bagian Tata Usaha, Direktur, Direktur Utama untuk diketahui dan diterima untuk pembayaran klaim tersebut. Setelah pimpinan menerima, maka selanjutnya pembayaran dilakukan oleh bagian keuangan.

Kompensasi yang dialokasikan dari perusahaan daerah yang mengatur parkir di daerah Denpasar atas konsumen saat mengalami kerugian dengan bentuk kehilangan kendaraan bermotor dapat dikatakan tidak seluruhnya dibiayai oleh pihak perusahaan daerah yang mengatur parkir di Kota Denpasar. Kewajiban yang dialokasikan oleh perusahaan daerah yang mengatur parkir di Kota Denpasar beritikad prinsip tanggung jawab pembatasan. Bentuk tanggung jawab yang diberikan oleh 
perusahaan daerah yang mengatur parkir di daerah Denpasar tak sepadan melalui yang tertulis dalam Pasal 19 U UPK dengan beritikad prinsip kewajiban seluruhnya. Kompensasi yang dialokasikan oleh perusahaan daerah yang mengatur parkir di Kota Denpasar harusnya sepadan berdasarkan tar if pasaran kendaraan bermotor yang hilang tersebut.

\section{SIMPULAN DAN SARAN}

\section{Simpulan}

Berdasarkan pembahasan diatas dapat disimpulkan bahwa upaya konsumen yang dirugikan saat mengupayakan ganti kerugian tentang ketiadaan alat transportasi di tempat dengan diambil retribusinya di Kota Denpasar bisa ditempuh dengan dua cara yaitu non litigasi (diluar pengadilan) dan litigasi (jalur pengadilan). Beberapa syarat untuk mendapatkan ganti rugi melalui non litigasi yaitu harus melampirkan berita acara kejadian dari perusahaan parkir Kota Denpasar, surat keterangan hilang dari kepolisian setempat, surat blokir kendaraan bermotor dari ditlantas Polda, buku pemilik kendaraan bermotor (BPKB), surat tanda nomor kendaraan (STNK), bukti karcis asli, foto copy kartu tanda penduduk (KTP), kunci kontak kendaraan yang hilang dan laporan kendaraan yang hilang diterima paling lambat 3×24 jam saat terjadinya kehilangan kendaraan bermotor. Syarat-syarat dalam penyelesaian sengketa melalui jalur litigasi laporan permohonan, laporan wewenang telah disahkan (seumpama memakai Advokat), gugatan dan laporan wewenang otentik wajib memperoleh izin oleh Ketua Pengadilan Negeri, berikutnya saat menerima izin, lalu penggugat / kuasanya melunasi tarif gugatan/SKUM (surat kuasa untuk membayar) di tempat pembayaran, memberikan SKUM yang sudah dilunasi serta menaruh bukti otentik sebagai dokumen, memperoleh petunjuk bukti perolehan laporan gugatan, menanti laporan undangan sidang oleh Pengadilan yang diberikan dari tukang Sita Pengganti, mendatangi sidang sepadan dari daftar yang sudah dipersiapkan. Dan mekanisme pertanggungjawaban sesuai dengan Pasal 11 PERDA No.11 Tahun 2005 tentang sistem penyelenggaraan perparkiran di Kota Denpasar yang menyebutkan dalam rangka memberikan jaminan dan keamanan, maka dalam hal wajib parkir kehilangan kendaraan bermotor pada waktu parkir di tempat- tempat parkir yang ditentukan sebagaimana dimaksud Pasal 3 Perda No 11 Tahun 2005, perusahaan daerah yang mengatur parkir memberikan bantuan kompensasi atas kerugian konsumen dalam bentuk kehilangan kendaraan bermotor dimaksud.Ganti rugi yang diberikan perusahaan daerah parkir Kota Denpasar melalui proses non litigasi. Setelah syarat-syarat yang diminta oleh perusahaan daerah yang mengatur parkir di Kota Denpasar dilengkapi oleh konsumen yang kehilangan kendaraan bermotor, selanjutnya mekanisme dari perusahaan yang mengatur parkir di Kota Denpasar dalam memberikan kompensasi yaitu santunan klaim ganti rugi dibayar paling lambat 7 (tujuh) hari sejak berkas pengajuan klaim disetujui, namun untuk kejadian bukan kehilangan kendaraan bukan kewajiban perusahaan daerah yang mengatur parkir di Kota Denpasar. Selanjutnya seksi pelaporan dan pengaduan melakukan cross cek ke lapangan kejadian, setelah melakukan cross cek akan dibuat berita acara kehilangan tentang pemeriksaan kehilangan kendaraan di lokasi kejadian dan berita acara tentang kehilangan kendaraan. Seksi pelapor dan pengaduan melaporkan ke pimpinan melalui Kepala bagian Tata Usaha, Direktur dan Direktur Utama untuk mendapat persetujuan. Tahap akhir pembayaran dilakukan oleh bagian keuangan.

\section{Saran}

Melalui penelitian ini penelit11ngin menyampaikan beberapa saran yang mungkin dapat membantu pemerintah untuk memperbaiki peraturan d11ndonesia. Melihat isi Pasal 11 PERDA No. 11Tahun 2005 berkenaan dengan penyelenggaraan perparkiran di daerah Denpasar yang memberikan ganti rugi apabila terjadi kehilangan kendaraan bermotor namun untuk kerusakan ada kehilangan atribut kendaraan bukan tanggung jawab perusahaan daerah parkir Kota Denpasar. Disarankan bagi pemerintah untuk memperbarui PERDA No. 11 tahun 2005 untuk memberikan kompensasi atas konsumen yang mendapati kerusakan dan kehilangan atribut kendaraan bermotor milik konsumen tersebut. Dan konsumen pengguna jasa parkir masih banyak yang tidak mengetahui PERDA No. 11 
Tahun 2005 tentang sistem penyelenggaraan perparkiran karena kurangnya sosialisasi perusahaan daerah yang mengatur parkir di Kota Denpasar. Sebaiknya, perusahaan daerah yang mengatur parkir di Kota Denpasar melakukan sosialisasi kepada konsumen pemakai jasa parkir di Kota Denpasar dan memberikan tulisan pada setiap lembar karcis tentang adanya PERDA No. 11 Tahun 2005 tersebut. Serta bagi konsumen pengguna jasa parkir disarankan untuk membaca dan memahami mekanisme pertanggungjawaban perusahaan daerah parkir Kota Denpasar dan apa saja syarat-s yarat yang harus konsumen lakukan apabila terjadi kerugian yang dialami konsumen saat kehilangan kendaraan bermotor parkir yang dipungut retribusinya agar mendapatkan ganti rugi berupa santunan sesuai dengan PERDA No. 11 Tahun 2005 tersebut.

\section{DAFTAR PUSTAKA}

Kristiyanti, C. T. S. (2018). Hukum perlindungan konsumen. Sinar Grafika. Jakarta. Meliala, A. (1993). Praktek Bisnis Curang. Pustaka Sinar Harapan. Jakarta.

Patrik, P. (1994). Dasar-Dasar Hukum Perikatan. Mandar Maju, Bandung.

Putra, J. K. (2018). Pertanggungjawaban Hukum Pelaku Usaha Penyedia Jasa Parkir Pada Hotel Jatra Kota Balikpapan Berdasarkan Prinsip Pertanggungjawaban Profesional. Jurnal Hukum Dejure, Vol.10(2).

Putra, I. B. K. A. D. (2020). Perlindungan Hukum terhadap Konsumen Parkir dalam Hal Terjadi Kehilangan di Area Parkir Lapangan Renon Kota Denpasar. Jurnal Preferensi Hukum, Vol.1(1).

Sardi, I. M. H. P., \& Agung, A. A. I. (2021). Penegakan Hukum terhadap Modifikasi Kendaraan Bermotor oleh Satuan Lalu Lintas Polres Gianyar. Jurnal Konstruksi Hukum, Vol.2(2), 2021.

Soejono, \& Abdurrahman. (2003). Metode Penelitian Hukum. Rineka Cipta. Jakarta.

Shidarta. (2000). Hukum Perlindungan Konsumen Indonesia. Grasindo. Jakarta.

Tamzil, T. (2019). Tanggung Jawab Hukum Perusahaan Daerah (PD) Parkir Makassar Raya kepada Konsumen yang Kehilangan Kendaraan Roda Dua (Motor). Jurnal Hukum Al-Hikam, Vol.6(1).

Tutik, T. T., \& Febriana, S. (2010). Perlindungan hukum bagi pasien. Prestasi Pustaka. Jakarta. 